\title{
Role of sea surface temperature responses in simulation of the climatic effect of mineral dust aerosol
}

\author{
X. Yue ${ }^{1,2, *}$, H. Liao ${ }^{3,1}$, H. J. Wang ${ }^{1,2}$, S. L. Li ${ }^{2}$, and J. P. Tang ${ }^{4,5}$ \\ ${ }^{1}$ Climate Change Research Center, Chinese Academy of Sciences (CAS), Beijing, China \\ ${ }^{2}$ Nansen-Zhu International Research Center, Institute of Atmospheric Physics, CAS, Beijing, China \\ ${ }^{3}$ State Key Laboratory of Atmospheric Boundary Layer Physics and Atmospheric Chemistry (LAPC), Institute of \\ Atmospheric Physics, CAS, Beijing, China \\ ${ }^{4}$ Key Laboratory of Middle Atmosphere and Global Environment Observation, Institute of Atmospheric Physics, CAS, \\ Beijing, China \\ ${ }^{5}$ Graduate University of CAS, Beijing, China \\ *now at: School of Engineering and Applied Sciences, Harvard University, Cambridge, Massachusetts, USA
}

Received: 23 November 2010 - Published in Atmos. Chem. Phys. Discuss.: 17 January 2011

Revised: 16 May 2011 - Accepted: 15 June 2011 - Published: 28 June 2011

\begin{abstract}
Mineral dust aerosol can be transported over the nearby oceans and influence the energy balance at the sea surface. The role of dust-induced sea surface temperature (SST) responses in simulations of the climatic effect of dust is examined by using a general circulation model with online simulation of mineral dust and a coupled mixed-layer ocean model. Both the longwave and shortwave radiative effects of mineral dust aerosol are considered in climate simulations. The SST responses are found to be very influential on simulated dust-induced climate change, especially when climate simulations consider the two-way dust-climate coupling to account for the feedbacks. With prescribed SSTs and dust concentrations, we obtain an increase of $0.02 \mathrm{~K}$ in the global and annual mean surface air temperature (SAT) in response to dust radiative effects. In contrast, when SSTs are allowed to respond to radiative forcing of dust in the presence of the dust cycle-climate interactions, we obtain a global and annual mean cooling of $0.09 \mathrm{~K}$ in SAT by dust. The extra cooling simulated with the SST responses can be attributed to the following two factors: (1) The negative net (shortwave plus longwave) radiative forcing of dust at the surface reduces SST, which decreases latent heat fluxes and upward transport of water vapor, resulting in less warming in the atmosphere; (2) The positive feedback between SST responses and dust cycle. The dust-induced reductions in SST lead to reductions in precipitation (or wet deposition of
\end{abstract}

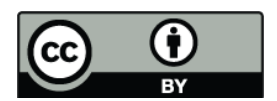

Correspondence to: Hong Liao (hongliao@mail.iap.ac.cn) dust) and hence increase the global burden of small dust particles. These small particles have strong scattering effects, which enhance the dust cooling at the surface and further reduce SSTs.

\section{Introduction}

Mineral dust aerosol is one of the major aerosol species in the atmosphere. While dust aerosol influences the Earth's energy balance through scattering and absorbing shortwave (SW) and longwave (LW) radiation (Carlson and Benjamin, 1980; Sokolik and Toon, 1996), dust-induced changes in meteorological parameters can feed back into dust cycle by altering emissions, transport, and deposition of dust (Miller et al., 2004a; Heinold et al., 2007). Such dust-climate interactions have been found to be important for simulations of dust-induced climate change (Yue et al., 2010).

When mineral particles are transported over the nearby oceans, they can influence the energy balance at the sea surface. Observational studies have shown that changes in dust concentrations correlate with those in sea surface temperature (SST). Lau and Kim (2007) found a significant negative correlation between the in situ measured dust concentrations in Barbados and SSTs over the Atlantic for the period of 1980-1999. Foltz and Mcphaden (2008), based on the measurements from the Moderate Resolution Imaging Spectroradiometer (MODIS), reported a significant decreasing trend in aerosol optical depth (AOD) over the tropical North Atlantic Ocean between 1980 and 2006, and found

Published by Copernicus Publications on behalf of the European Geosciences Union. 
Table 1. Simulations of climatic effect of dust in previous studies.

\begin{tabular}{|c|c|c|c|}
\hline References & SST responses & $\begin{array}{l}\text { On-line dust } \\
\text { simulation }\end{array}$ & global \\
\hline Miller et al. (2004a) & yes $(\mathrm{SW}+\mathrm{LW})^{*}$ & yes & yes \\
\hline Mahowald et al. (2006) & yes (SW + LW) & yes & yes \\
\hline Miller et al. (2004b) & yes (SW + LW) & yes & no \\
\hline Yoshioka et al. (2007) & yes $(\mathrm{SW}+\mathrm{LW})$ & yes & no \\
\hline Miller and Tegen (1998) & yes (SW + LW) & no & yes \\
\hline Shell and Somerville (2007) & yes (SW + LW) & no & yes \\
\hline Perlwitz and Miller (2010) & yes $(\mathrm{SW}+\mathrm{LW})$ & no & yes \\
\hline Evan et al. (2008) & yes $(\mathrm{SW})^{* *}$ & no & no \\
\hline Perlwitz et al. (2001) & no $(\mathrm{SW}+\mathrm{LW})$ & yes & yes \\
\hline Heinold et al. (2007) & no $(\mathrm{SW}+\mathrm{LW})$ & yes & no \\
\hline Ahn et al. (2007) & no $(\mathrm{SW})$ & yes & no \\
\hline Helmert et al. (2007) & no $(\mathrm{SW}+\mathrm{LW})$ & yes & no \\
\hline Konare et al. (2008) & no $(\mathrm{SW})$ & yes & no \\
\hline Solmon et al. (2008) & no $(\mathrm{SW}+\mathrm{LW})$ & yes & no \\
\hline Zhang et al. (2009) & no $(\mathrm{SW}+\mathrm{LW})$ & yes & no \\
\hline Lau et al. (2006) & no $(\mathrm{SW}+\mathrm{LW})$ & no & no \\
\hline Collier and Zhang (2009) & no $(\mathrm{SW})$ & no & no \\
\hline
\end{tabular}

* SW + LW means the study considers both SW and LW RF of dust.

${ }^{* *} \mathrm{SW}$ means the study considers only SW RF of dust.

that this trend was correlated with the increases in SST over the same region in the same time period. Similarly, Luo et al. (2009) found that the observed increases in SST over the subtropical Atlantic were correlated to the satellite retrieved declines in AOD over the same region during 19852006. Evan et al. (2009) used 26-year of satellite data of AOD as the input of a climate model and found that the regional variation of aerosols can account for $69 \%$ of the recent upward trend in SST over the northern tropical Atlantic Ocean. Avellaneda et al. (2010) analyzed the retrievals of AOD from MODIS and of SST from the Tropical Rainfall Measuring Mission (TRMM) satellite, and found a decrease of $0.2-0.4 \mathrm{~K}$ in SST over the eastern subtropical North Atlantic shortly after the outbreak of a strong dust storm in the Sahara Desert. These studies underscore the importance of considering SST responses in simulations of the climatic effect of dust.

Previous global or regional modeling studies on the climatic effect of dust, as summarized in Table 1, include climate simulations with fixed SSTs (Perlwitz et al., 2001; Lau et al., 2006; Ahn et al., 2007; Heinold et al., 2007; Helmert et al., 2007; Konare et al., 2008; Solmon et al., 2008; Collier and Zhang, 2009; Zhang et al., 2009) and those that considered the SST responses to radiative forcing (RF) of dust using a mixed-layer or a dynamic ocean model (Miller and Tegen, 1998; Miller et al., 2004a,b; Mahowald et al., 2006; Shell and Somerville, 2007; Yoshioka et al., 2007; Evan et al., 2008; Perlwitz and Miller, 2010). Among the seven studies with SST responses, Miller and Tegen (1998) examined the role of SST responses in simulated dust-induced climate change using prescribed dust concentrations and found moderate differences in simulated climatic effect of dust between simula- tions with and without SST responses. Miller et al. (2004b) reported that dust-induced SST responses have a large impact on evaporation at the surface and consequently on dust emissions over the Arabian Peninsula during the Asian summer monsoon using a general circulation model (GCM). No previous studies, to our knowledge, have investigated the role of dust-induced SST responses in simulated climatic effect of dust with the two-way dust cycle-climate interactions.

We seek to understand the role of dust-induced SST responses in simulation of the climatic effect of dust using a GCM with/without the two-way dust-climate coupling, focusing on the differences in simulated dust-induced changes in temperature and precipitation in the presence and absence of SST responses. The two-way dust-climate coupling is emphasized here because the feedbacks among dust-climateSST are the keys for understanding model results. This study builds on our previous work, in which a Global Transport Model of Dust (GMOD) was developed (Yue et al., 2009) and climate responses to both the SW and LW radiative effects of dust were examined (Yue et al., 2010). In the following section, we present a brief description of the GCM, dust simulation, the consideration of dust radiative effects, and our numerical experiments. The simulated dust cycle and its RF are shown in Sect. 3. The simulated climatic effects are presented and discussed in Sect. 4.

\section{The model and numerical experiments}

\subsection{The models}

The climate model IAP9L-AGCM has a horizontal resolution of $4^{\circ} \times 5^{\circ}$ with nine vertical levels up to $10 \mathrm{hPa}$ (Zeng et al., 1989; Zhang, 1990; Liang, 1996). It is coupled with a mixed-layer ocean model from Hansen et al. (1984) and utilizes an annual mean mixed-layer depth derived from Levitus et al. (2000). The GCM has been used in simulations of global monsoon systems (Chidiezie et al., 1997; Xue et al., 2001), interannual and decadal climatic dynamics (Mu and Li, 1999; Zhu et al., 2010), and paleoclimate (Jiang et al., 2003; Zhang et al., 2007; Yue et al., 2011).

The dust model GMOD was integrated into the GCM to simulate the global transport of dust aerosol in Yue et al. (2009). The GMOD simulates four dust bins with dry radii covering $0.1-1.0,1.0-2.0,2.0-5.0$, and $5.0-10.0 \mu \mathrm{m}$. The dust emission scheme follows that in Wang et al. (2000), with dust uplift flux calculated as a function of meteorological parameters such as friction velocity and relative humidity $(\mathrm{RH})$ of the air near surface. The dependence of dust emission on RH is a unique feature of the GMOD (Yue et al., 2010). Dust sources are determined by land surface types in the GCM; deserts, scrubland, and short grassland are allowed to have dust emissions.

We further updated the radiative scheme in IAP9L-AGCM to consider the radiative effects of dust aerosol (Yue and 
Wang, 2009; Yue et al., 2010). The scheme utilizes the $\delta$-Eddington approximation in solar spectra (Briegleb, 1992) and the parameterizations of Ramanathan and Downey (1986) for absorptivity and emissivity of the atmospheric trace gases in the thermal spectra. We utilize an exponential transmission approximation (Carlson and Benjamin, 1980) to consider the impact of dust on the atmospheric transmission in the LW region (Yue et al., 2010). The refractive indices of dust follow those in Woodward (2001), which were compiled based on measurements at different locations of the world. The optical properties of dust are calculated using the Mie Theory.

\subsection{Numerical experiments}

We perform two groups of simulations to investigate the impacts of the SST responses on the simulated climatic effects of dust. The first group of simulations have fixed monthly SSTs (denoted as FIXSST) during the simulation. These experiments lack a surface energy constraint, hence the surface forcing by dust is nearly uncompensated by the surface energy exchanges, and the sensible and latent heat fluxes vary following the changes in air temperature, wind speed, and air humidity. In the other group of simulations, the SSTs are allowed to respond to the energy exchanges at the surface by using a mixed-layer ocean model (denoted as MXLSST). In each group, three separate sensitivity experiments are carried out to further explore the impact of SST responses with or without the interactions between dust cycle and climate (Fig. 1): (1) The control (CTRL) experiment that simulates both dust cycle and climate, with dust radiative effects not allowed to feed back into the GCM climate, (2) the fixed dust (FD) experiment that simulates climate responses to the RF of prescribed monthly mean concentrations of dust, which are obtained from the CTRL run, and (3) the coupled dust (CD) experiment with the two-way coupling between dust cycle and climate.

In each group of simulations, the differences in climate between the FD and CTRL experiments represent the climatic effects of dust with prescribed concentrations, and the differences between CD and CTRL represent climate responses to $\mathrm{RF}$ of the interactive dust. With the two groups of simulations, we can examine (FD - CTRL) and (CD - CTRL) with or without SST responses.

To reduce the model sensitivity to initial conditions, each experiment in either FIXSST or MXLSST group is an ensemble of three climate simulations; the ensemble means of the simulated climatology of dust cycle and meteorological parameters are presented. While the simulated annual and global mean surface air temperature (SAT) reaches equilibrium very fast for each run in FIXSST group, the slow responses of the oceans lead to a longer time for climate to reach equilibrium in the MXLSST group of simulations. As a result, the ensemble runs for FIXSST_CTRL, FIXSST_FD, and FIXSST_CD are integrated for 25 years,

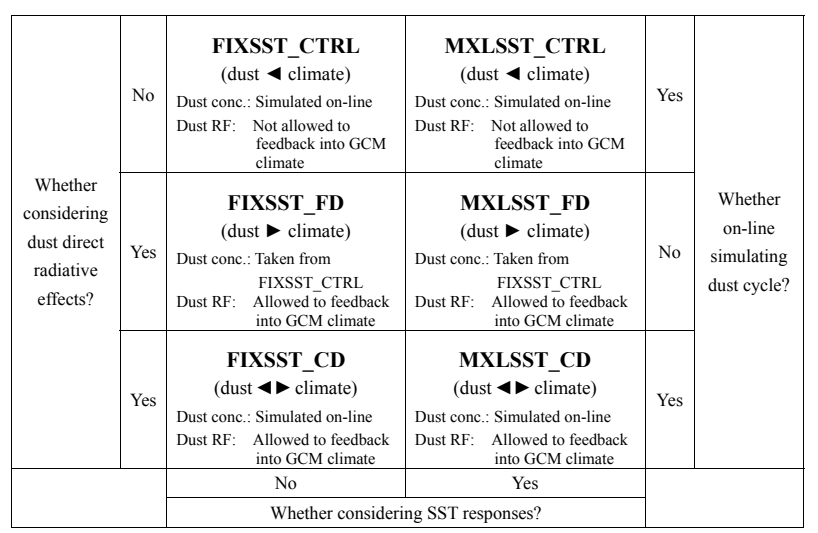

Fig. 1. Summary of numerical experiments.

respectively, with the first 5 model years used as spin-up. The ensemble runs for MXLSST_CTRL, MXLSST_FD, and MXLSST_CD are integrated for 50 years, respectively, with the first 20 model years used as the spin-up period. Such approach of having different years of integration for simulations with/without SST responses was also used in the study of Miller and Tegen (1998). In the following discussions, we rule out the spin-up period for each run to analyze the equilibrium climate responses to the dust radiative effects. The Student-t test is used to examine the significance level of the differences between different experiments. In reference to seasonality, four boreal seasons from spring to winter are denoted as MAM (MarchMay), JJA (June-August), SON (September-November), and DJF (December-February).

\section{Simulated dust cycle and radiative forcing}

\subsection{Dust cycle}

On a global scale, experiment FIXSST_CTRL predicts an annual dust emission of 2005 trillion gram $\left(\mathrm{Tg}, 1 \mathrm{Tg}=10^{12} \mathrm{~g}\right)$ for four dust bins, in which $1354 \mathrm{Tg}$ is dry deposited and $650 \mathrm{Tg}$ is wet deposited (Table 2). The simulated annual mean dust burden of $28.8 \mathrm{Tg}$ is within the range of $12.1-$ $35.8 \mathrm{Tg}$ estimated by previous studies (e.g., Ginoux et al., 2001; Zender et al., 2003; Liao et al., 2004; Reddy et al., 2005). The average lifetime of dust particles is simulated to be 5.2 days; small particles (radius $r<1.0 \mu \mathrm{m}$ ) can stay in the atmosphere for about 21 days, while large particles (radius $r \geq 5.0 \mu \mathrm{m}$ ) are removed from the atmosphere within about 1 day (Yue et al., 2009).

Simulated column burdens of dust in FIXSST_CTRL are shown in Fig. 2. Dust aerosol has high concentrations over source regions, such as the Sahara Desert, Central Asia, and the Australian deserts. Vertically, dust particles of different size extend to different heights (Fig. 3). The smallest 
Table 2. Simulated dust climatology in different numerical experiments *.

\begin{tabular}{llllll}
\hline Experiments & $\begin{array}{l}\text { Uplift } \\
\left(\mathrm{Tg} \mathrm{yr}^{-1}\right)\end{array}$ & $\begin{array}{l}\text { Dry } \\
\text { deposition } \\
\left(\mathrm{Tg} \mathrm{yr}^{-1}\right)\end{array}$ & $\begin{array}{l}\text { Wet } \\
\text { deposition } \\
\left(\mathrm{Tg} \mathrm{yr}^{-1}\right)\end{array}$ & $\begin{array}{l}\text { Burden } \\
(\mathrm{Tg})\end{array}$ & $\begin{array}{l}\text { Lifetime } \\
(\text { days })\end{array}$ \\
\hline FIXSST_CTRL & $2005 \pm 45$ & $1354 \pm 30$ & $650 \pm 15$ & $28.8 \pm 0.9$ & $5.2 \pm 0.1$ \\
FIXSST_CD & $1931 \pm 47$ & $1301 \pm 32$ & $629 \pm 16$ & $31.8 \pm 1.1$ & $6.0 \pm 0.1$ \\
MXLSST_CTRL & $1915 \pm 76$ & $1290 \pm 51$ & $625 \pm 25$ & $27.4 \pm 1.3$ & $5.2 \pm 0.1$ \\
MXLSST_CD & $1869 \pm 72$ & $1259 \pm 49$ & $610 \pm 24$ & $30.7 \pm 1.5$ & $6.0 \pm 0.1$ \\
\hline
\end{tabular}

${ }^{*}$ Results are shown as $\bar{x} \pm \sigma$, where $\bar{x}$ and $\sigma$ are, respectively, the mean value and the standard deviation in 20 years of FIXSST experiments and 30 years of MXLSST simulations.

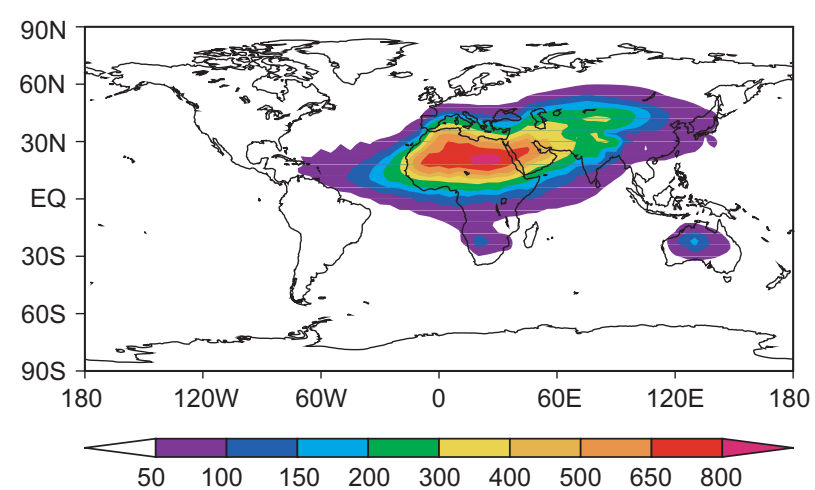

Fig. 2. Annual mean column burden of dust aerosol simulated in the control experiment with fixed SST (FIXSST_CTRL). Unit: $\mathrm{mg} \mathrm{m}^{-2}$.

particles can reach stratosphere and travel far away from the source regions (Fig. 3a). The largest particles are constrained at the low levels near the sources because of their large gravitational settling velocity (Fig. 3d). The simulated vertical profiles are qualitatively consistent with the model results in Tegen and Fung (1994) and the observations in Ginoux et al. (2001) and Huang et al. (2008).

The simulated dust cycle in FIXSST_CTRL has been evaluated by comparing with measurements in Yue et al. (2009). The GCM reproduces reasonably well the dust concentrations at 18 sites (mean bias (MB) of $-0.67 \mu \mathrm{g} \mathrm{m}^{-3}$, normalized mean bias (NMB) of $-8.0 \%$ ), aerosol optical depth at 16 sites (MB of $-0.04, \mathrm{NMB}$ of $-26.7 \%$ ), and deposition of dust at 251 sites with a logarithmic correlation coefficient of 0.84 between the simulated and measured values. The simulated annual and global mean dust optical depth at $0.55 \mu \mathrm{m}$ is 0.032 , which is close to the values of 0.030 by Tegen and Lacis (1996) and 0.037 by Liao et al. (2004).

\subsection{Radiative forcing of dust}

The SW and LW RFs of dust aerosol are calculated offline using the "double radiation call" method following Woodward (2001), based on the simulated dust concen- trations from FIXSST_CTRL. Since the estimated RF values have been presented in detail in Yue et al. (2010), we summarize our RF values here for understanding the simulated climate responses to dust RF. The simulated single scattering albedo (SSA) of the dust particles is 0.94 at $0.63 \mu \mathrm{m}$ on a global mean basis, using the imaginary parts of the refractive indices of dust compiled by Woodward (2001). As a result, dust aerosol is estimated to exert global and annual mean SW and LW RFs of, respectively, $-0.34 \mathrm{~W} \mathrm{~m}^{-2}$ and $+0.31 \mathrm{~W} \mathrm{~m}^{-2}$ at the top of the atmosphere (TOA) and $-2.20 \mathrm{~W} \mathrm{~m}^{-2}$ and $+0.70 \mathrm{~W} \mathrm{~m}^{-2}$ at the surface. The net $(\mathrm{SW}+\mathrm{LW})$ TOA RFs are positive over the Sahara Desert (c.f. Fig. 2e in Yue et al., 2010), because of the LW absorption by large dust particles and the SW absorption over high-albedo surface (Yue et al., 2010). The net TOA RFs are negative over the tropical Atlantic and the Indian Ocean, where the surface albedo is low. At the surface, the particles lead to a general net negative forcing, with a maximum cooling of $15.0 \mathrm{~W} \mathrm{~m}^{-2}$ over the Sahara Desert (c.f. Fig. $2 \mathrm{f}$ in Yue et al., 2010). The RF values at both the TOA and surface were compared with estimates in other models in Yue et al. (2010).

\section{Impact of SST responses on simulated climatic effect of dust}

In this section, the impacts of dust-induced SST responses on simulated climatic effect of dust are presented firstly for simulations with prescribed dust concentrations and then for those with interactive dust. The feedbacks with/without dustclimate coupling will be summarized and discussed at the end of this section.

\subsection{Climate responses with prescribed dust concentrations}

\subsubsection{Temperature}

The impact of SST responses on simulated SAT is examined by comparing the differences between (FIXSST_FD - FIXSST_CTRL) (Fig. 4a) and (MXLSST_FD - 
(a) Dust ( $r .0 .1-1.0 \mu m)$

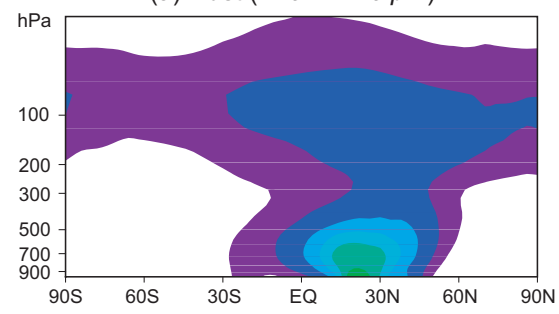

(c) Dust ( $r .2 .0-5.0 \mu \mathrm{m})$

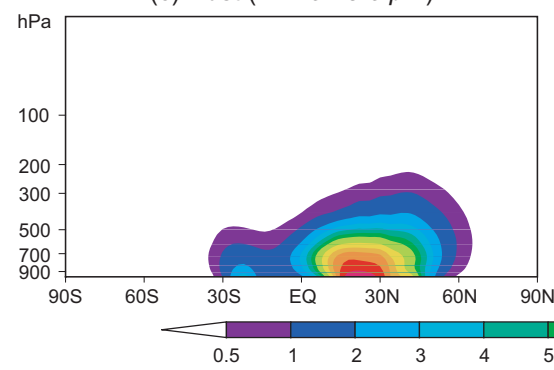

(b) Dust $(r .1 .0-2.0 \mu m)$

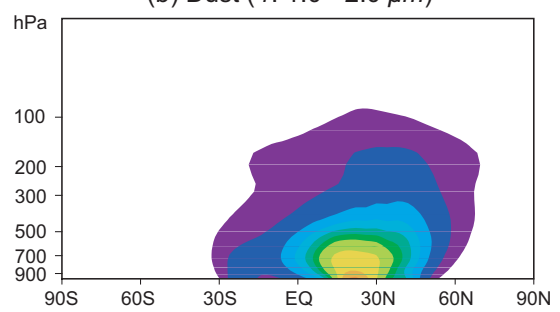

(d) Dust ( r: $5.0-10.0 \mu \mathrm{m})$

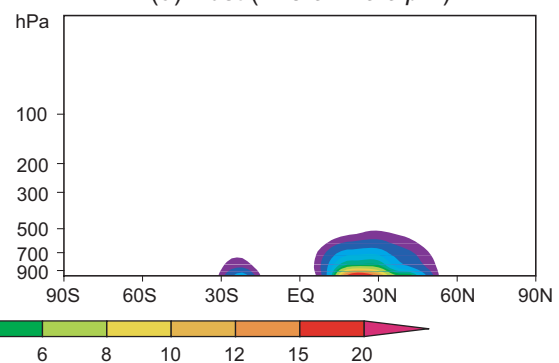

Fig. 3. Annual zonal mean concentrations of dust with radius at (a) $0.1-1.0 \mu \mathrm{m}$, (b) $1.0-2.0 \mu \mathrm{m}$, (c) $2.0-5.0 \mu \mathrm{m}$, and (d) $5.0-10.0 \mu \mathrm{m}$ simulated in the control experiment with fixed SST (FIXSST_CTRL). Unit: $\mu g$ dust per Kg air.

MXLSST_CTRL) (Fig. 4e), which represent the simulated responses in SAT to the net RF of prescribed dust with FIXSST and MXLSST, respectively. Over Africa, the pattern of dust-induced changes in SAT with FIXSST is similar to that simulated with MXLSST. A maximum warming of $0.3-0.7 \mathrm{~K}$ is found over northern Africa $\left(10^{\circ} \mathrm{W}-\right.$ $30^{\circ} \mathrm{E}, 15^{\circ}-30^{\circ} \mathrm{N}$ ) in both cases, which can be explained by the SW absorption of dust over high-albedo surface and LW absorption by large dust particles over this area. Our simulated warming in northern Africa agrees with the simulations by Carlson and Benjamin (1980) and Weaver et al. (2002).

Over the tropical oceans, simulated dust-induced changes in SAT with FIXSST are quite different from those with MXLSST. With FIXSST, SAT responses are positive over the Atlantic and the Indian Ocean (Fig. 4a) where dust particles transported from the Sahara Desert and the Arabian Peninsula have high concentrations. With MXLSST, however, SSTs respond to negative dust RF at the surface, leading to statistically significant negative SAT responses of about $-0.1 \mathrm{~K}$ over the tropical oceans (Fig. $4 \mathrm{e}$ ). On a global and annual mean basis, the net RF of prescribed dust leads to a warming of $0.02 \mathrm{~K}$ in SAT with FIXSST but a cooling of $0.03 \mathrm{~K}$ with MXLSST. The seasonal responses in SAT to dust radiative effect are shown in Table 3. In all seasons, dustinduced changes in SAT are negative with SST responses whereas positive in simulations with fixed SST, which agree with our conclusions based on annual mean SAT. With SST responses, the dust-induced cooling are stronger in SON and DJF than in MAM.
The simulated atmospheric temperatures also show different responses to the net RF of prescribed dust, as the case with FIXSST is compared to that with MXLSST. In FIXSST_FD, dust aerosol leads to a general warming in the middle-upper troposphere (Fig. 4b), similar to the result of Carlson and Benjamin (1980) that was also simulated with prescribed SSTs. In MXLSST_FD, dust-induced warming is weakened in the middle-upper troposphere and a cooling is simulated to stretch from the surface to the middle troposphere over $90^{\circ} \mathrm{S}-30^{\circ} \mathrm{N}$ (Fig. 4f).

The different responses in atmospheric temperature to about the same net RF of dust in FIXSST and MXLSST can be attributed to the differences in SST responses. In FIXSST_FD, SSTs are fixed during the climate simulation; hence the changes in latent and sensible heat fluxes between the oceans and the atmosphere are dependent on the changes in meteorological parameters of the surface air. In MXLSST_FD, however, energy fluxes between the oceans and the atmosphere are determined by the changes in both the oceans and the atmosphere. As shown in Fig. 5, the pattern of the changes in sensible heat flux in FIXSST_FD is similar to that in MXLSST_FD. Over the oceans, while the reductions in the upward sensible heat flux in FIXSST_FD (Fig. 5a) result from the dust-induced increases in SAT (Fig. 4a), the reductions in MXLSST_FD (Fig. 5c) are a result of the changes in both SST and SAT (the reductions in SST are larger than the reductions in SAT). The changes in latent heat flux from the ocean to the atmosphere are dependent on the differences between saturated humidity at the ocean surface and surface air humidity. Over the oceans, the reductions in latent heat flux in FIXSST_FD (Fig. 5b) result 
(a) $\triangle$ SAT FIXSST FD (0.02)

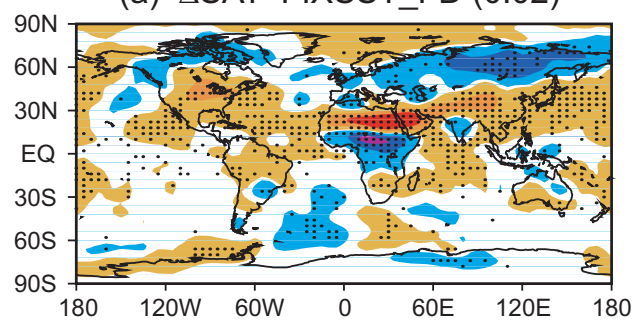

(b) $\Delta \mathrm{T} \quad$ FIXSST_FD (0.09)

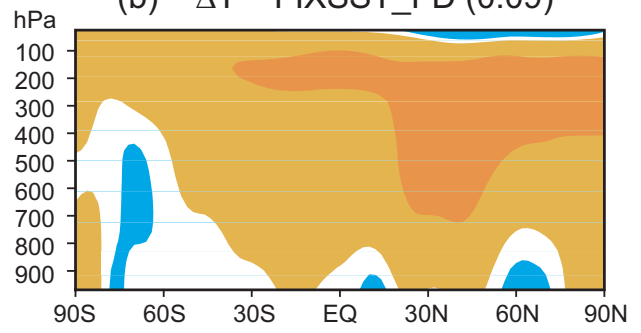

(c) $\triangle Q$ FIXSST_FD (0.017)

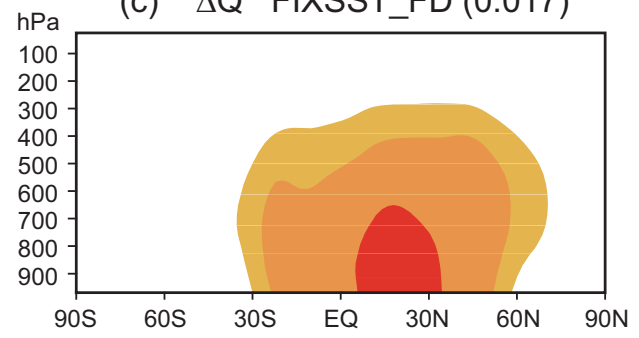

(d) $\triangle$ Prec FIXSST_FD (-0.01)

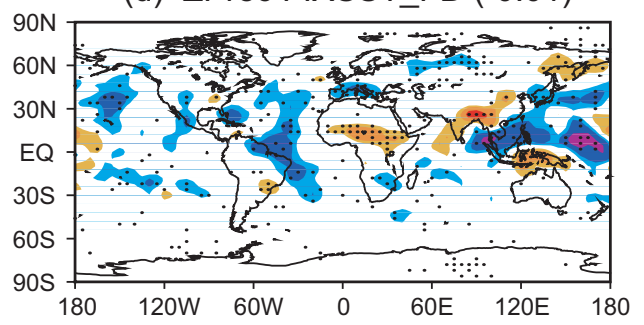

(e) $\triangle$ SAT MXLSST FD (-0.03)

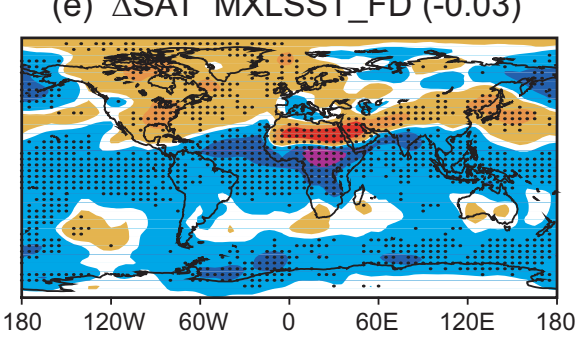

(f) $\Delta T \quad$ MXLSST_FD (0.02)

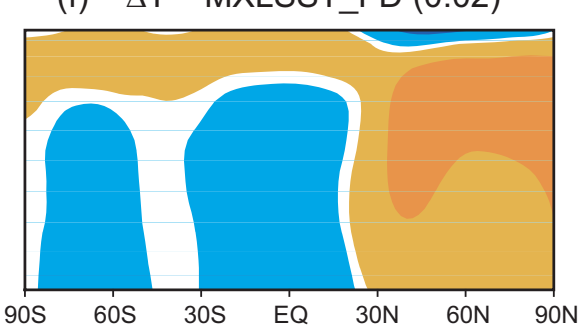

(g) $\triangle Q$ MXLSST_FD (-0.002)

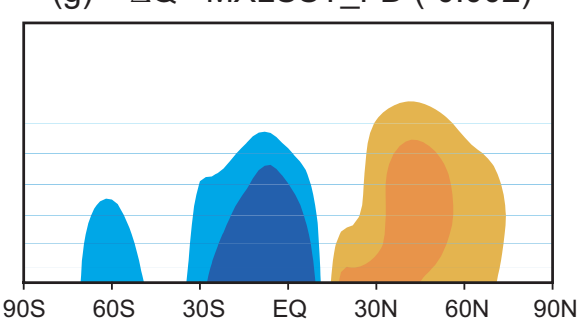

(h) $\triangle$ Prec MXLSST_FD (-0.02)

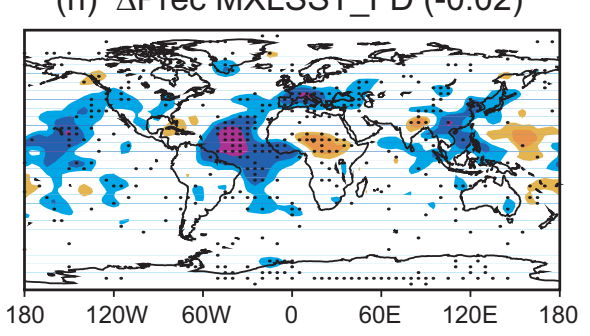

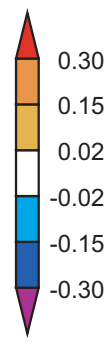
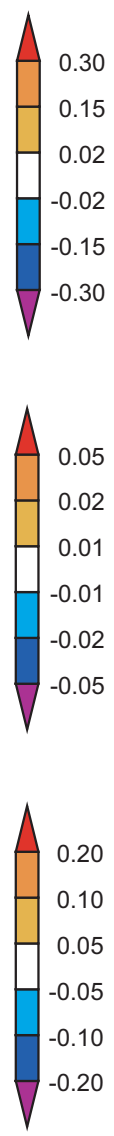

Fig. 4. Simulated dust-induced changes in annual mean surface air temperature (K, top row), annual and zonal mean air temperature (K, second row), annual and zonal mean specific humidity $\left(\mathrm{g} \mathrm{kg}^{-1}\right.$, third row), annual mean precipitation (mm day ${ }^{-1}$, bottom row). Left panels: Dust-induced changes in meteorological fields with fixed dust density and fixed SST (FIXSST_FD - FIXSST_CTRL). Right panels: dustinduced changes with the mixed-layer ocean and fixed dust density (MXLSST_FD - MXLSST_CTRL). The global mean values are shown in the brackets. Differences that pass the $95 \%$ significance level are denoted with dots.

from the dust-induced increases in SAT which allow the air to hold more water, whereas the reductions in latent heat flux in MXLSST_FD (Fig. 5d) are mainly caused by the dustinduced reductions in SSTs and hence in saturated humidity at the ocean surface. For both sensible and latent heat fluxes, the negative changes over the tropical oceans are more significant in MXLSST_FD than in FIXSST_FD (Fig. 5). As a result, in the case of MIXSST_FD, the atmospheric cooling by the reduced water vapor content (Fig. $4 \mathrm{~g}$ ) and the reduced upward sensible heat fluxes exceeds the atmospheric heating by LW and SW effect of dust, leading to a net cooling over the tropical oceans.

\subsubsection{Hydrological cycle}

As mentioned above, the dust-induced increases in air temperature strengthen the capability of the atmosphere to hold water vapor, leading to a large increase in air humidity in FIXSST_FD (Fig. 4c). In MXLSST_FD, air 
(a) $\triangle$ SH FIXSST_FD (-0.64)

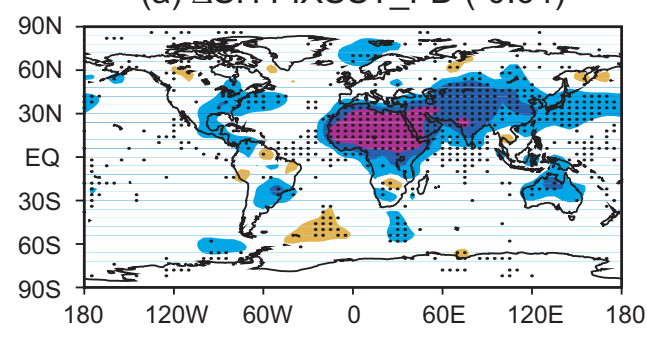

(b) $\triangle$ LH FIXSST_FD (-0.39)

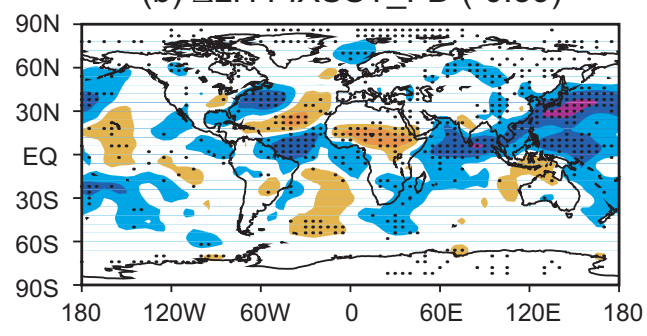

(c) $\triangle$ SH MXLSST_FD (-0.54)

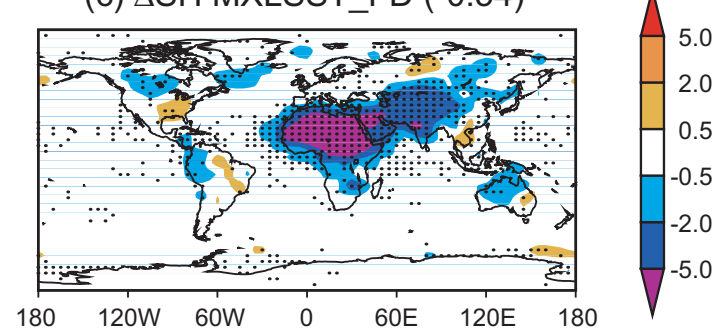

(d) $\triangle$ LH MXLSST_FD (-0.62)

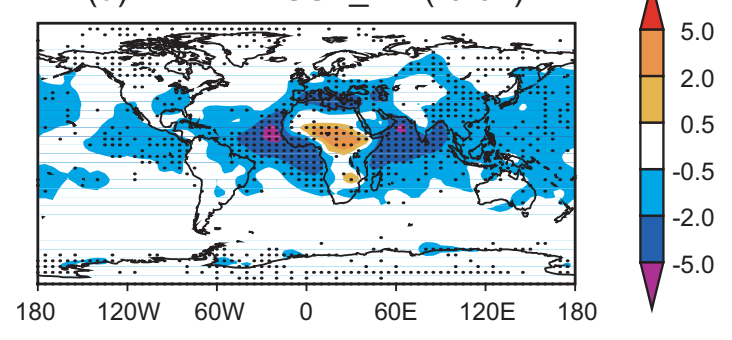

Fig. 5. Simulated dust-induced changes in annual mean sensible heat flux ( $\mathrm{W} \mathrm{m}^{-2}$, top row) and latent heat flux (W $\mathrm{m}^{-2}$, bottom row). Left panels: Dust-induced changes in heat fluxes with fixed dust density and fixed SST (FIXSST_FD - FIXSST_CTRL). Right panels: Dustinduced changes with the mixed-layer ocean and fixed dust density (MXLSST_FD - MXLSST_CTRL). The global mean values are shown in the brackets. Differences that pass the $95 \%$ significance level are denoted with dots.

humidity exhibits a widespread decrease over the tropical oceans (Fig. $4 \mathrm{~g}$ ) because of the reductions in evaporation and in air temperature (Fig. 4f).

The dust-induced changes in clouds are associated with the dust-induced changes in temperature and atmospheric circulation (Rodwell and Jung, 2008), especially on a regional scale. The strong surface warming over the Sahara Desert $\left(0^{\circ}-30^{\circ} \mathrm{E}, 18^{\circ}-30^{\circ} \mathrm{N}\right)$ increases temperature lapse rate and reduces atmospheric stability, leading to an increase in vertical velocity (Fig. 6a). On the other hand, the dust-induced increases in air temperature at high altitudes (Fig. 4b) enhance atmospheric stability between $30^{\circ}-$ $45^{\circ} \mathrm{N}$, leading to a regional anomalous subsidence (Fig. 6a). In response to such changes in the regional Hadley circulation, in the simulation of FIXSST_FD, the middle cloud amount (MCA) shows decreases over the regions north of the Sahara Desert (Fig. 6b), and the high cloud amount (HCA) exhibits increases in the central Sahara Desert and the Arabian Desert (Fig. 6c). The low cloud amount is predicted to have practically no change over the northern Africa (not shown). On a global scale, the atmospheric stability is increased by the dominant warming at high levels (Fig. 4b), resulting in annual mean decreases in MCA and HCA by $0.08 \%$ and $0.02 \%$, respectively, in FIXSST_FD. In the case of MXLSST_FD, similar changes in MCA and HCA are found with similar changes in regional Hadley circulation (Fig. 6d-f). Our model results of the regional changes in HCA agree with those reported in Perlwitz and Miller (2010).
The changes in the amount of middle cloud (typically water cloud) and in latent heat flux contribute to the changes in precipitation (Figs. 4d and $4 \mathrm{~h}$ ). The pattern of dustinduced changes in precipitation in FIXSST_FD (Fig. 4d) is generally similar to that in MXLSST_FD (Fig. 4h), but the simulated changes over Europe, the tropical Pacific Ocean, and the tropical Atlantic Ocean are larger in MXLSST_FD. Our simulated strong sensitivity of precipitation to SST responses is consistent with that found in Yang et al. (2003), who investigated the different impacts of fixed and calculated SSTs on simulated changes in precipitation under global warming scenarios. The differences in precipitation between FIXSST_FD and MXLSST_FD are also found over the north of the Bay of Bengal. Large increases in precipitation are predicted over the north of the Bay of Bengal in FIXSST_FD (Fig. 4d), which agree with the dustinduced anomalous increases in rainfall in this region reported by Miller and Tegen (1998) and Lau et al. (2006). These two studies used prescribed SST but different climate models. Over the north of the Bay of Bengal, the positive rainfall anomalies are weakened in MXLSST_FD, because the dust-induced increases in temperature in the middle troposphere (or the "heating pump" effects proposed by Lau et al., 2006) are smaller in MXLSST_FD than in FIXSST_FD.

It should be noted that the dust-induced changes in hydrological cycle feed back into simulated changes in temperature. First, because water vapor is an important greenhouse gas in the troposphere, the changes in air humidity have a positive feedback on air temperature. While the simulated 
(a) $\Delta \omega \quad$ FIXSST_FD

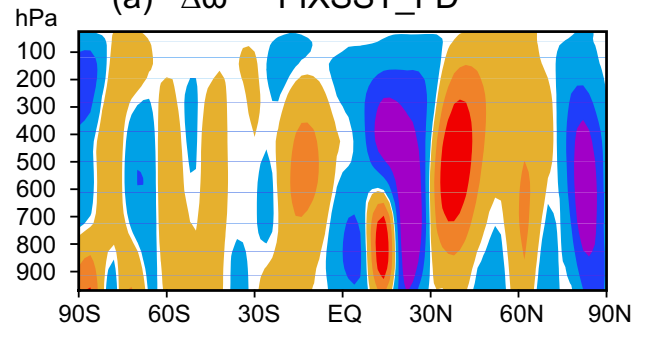

(b) $\triangle$ MCA FIXSST_FD (-0.08)

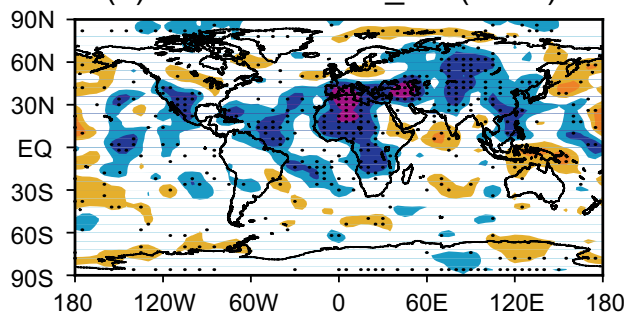

(c) $\triangle$ HCA FIXSST_FD (-0.02)

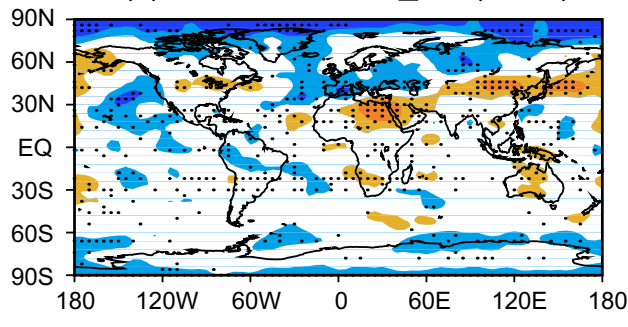

(d) $\Delta \omega$

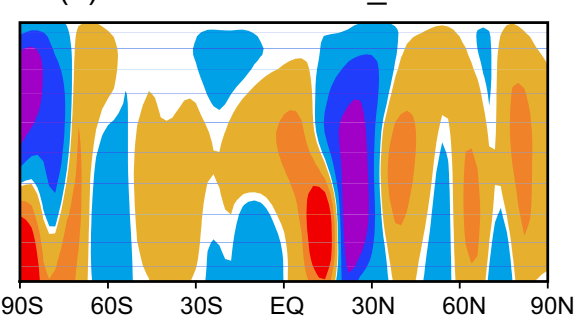

(e) $\triangle$ MCA MXLSST_FD (-0.09)

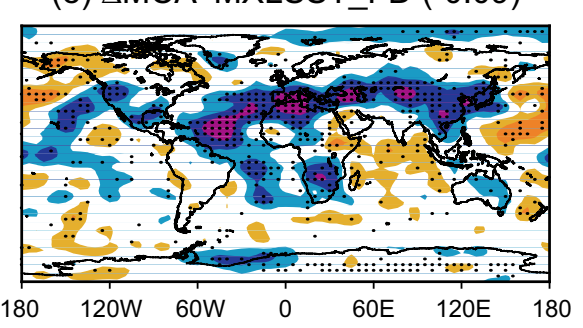

(f) $\triangle$ HCA MXLSST_FD (-0.04)

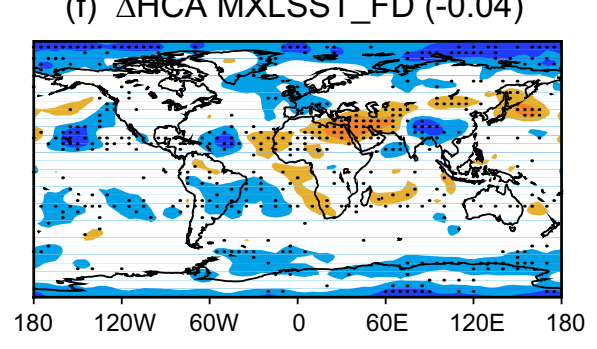

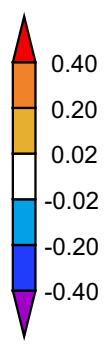
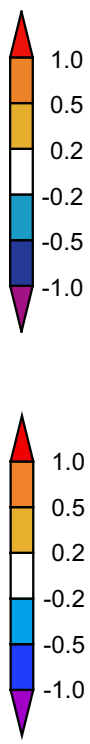

Fig. 6. Simulated dust-induced changes in annual and zonal mean vertical velocity between $60^{\circ} \mathrm{W}-60^{\circ} \mathrm{E}$ (hPa day ${ }^{-1}$, top row), annual mean middle cloud amount ( $\%$, middle row), and annual mean high cloud amount (\%, bottom row). Left panels: dust-induced changes in meteorological fields with fixed dust density and fixed SST (FIXSST_FD - FIXSST_CTRL). Right panels: dust-induced changes with the mixed-layer ocean and fixed dust density (MXLSST_FD - MXLSST_CTRL).

increases in air humidity contribute to the simulated dustinduced atmospheric warming in FIXSST_FD (Fig. 4b and c), the reductions in air humidity enhance the atmospheric cooling in MXLSST_FD (Fig. 4f and g). Second, the changes in clouds contribute to the temperature responses regionally. In both FIXSST_FD and MXLSST_FD, the dust-induced decreases in MCA over Asia enhance the surface warming in that region (Fig. 4a and e). Such semi-direct effect of aerosol increases the complexity of climate responses to aerosol forcing (Gu et al., 2006).

\subsection{Climate responses with two-way dust-climate coupling}

\subsubsection{Temperature}

With the two-way dust-climate coupling, the impact of SST responses on simulated climatic effect of dust can be examined by comparing the differences between (FIXSST_CD - FIXSST_CTRL) (Fig. 7a-d) and (MXLSST_CD -
Table 3. Simulated dust-induced global mean changes in SAT in different seasons. Units: K.

\begin{tabular}{lrrrr}
\hline Experiments & MAM & JJA & SON & DJF \\
\hline FIXSST_FD & 0.01 & 0.04 & 0.01 & 0.00 \\
FIXSST_CD & 0.02 & 0.04 & 0.01 & 0.00 \\
MXLSST_FD & -0.03 & -0.02 & -0.03 & -0.05 \\
MXLSST_CD & -0.08 & -0.07 & -0.09 & -0.11 \\
\hline
\end{tabular}

MXLSST_CTRL) (Fig. 7e-h). The dust-induced changes in SAT in FIXSST_CD (Fig. 7a) are similar to those in FIXSST_FD (Fig. 4a), with a global and annual mean change of $+0.02 \mathrm{~K}$. The simulated SAT responses to dust RF in MXLSST_CD (Fig. 7e) differ from those in FIXSST_CD (Fig. 7a). Experiment MXLSST_CD predicts a general surface cooling of $0.15-0.30 \mathrm{~K}$ over the tropical oceans (Fig. 7e) and a zonal mean cooling extending from the 
(a) $\triangle$ SAT FIXSST_CD (0.02)

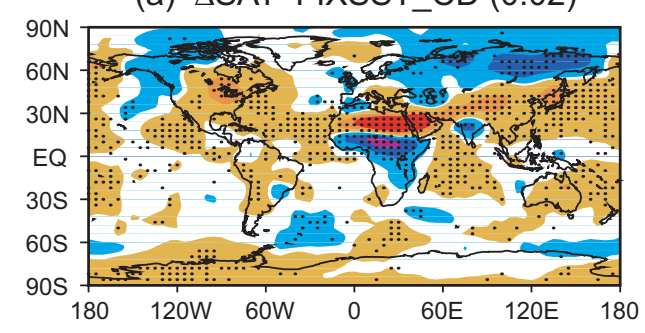

(b) $\Delta \mathrm{T} \quad$ FIXSST_CD (0.11)

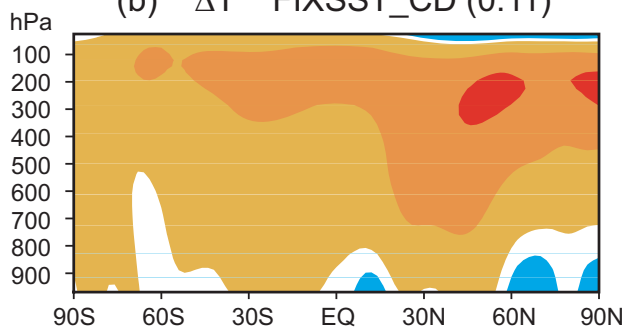

(c) $\triangle Q$ FIXSST_CD (0.020)

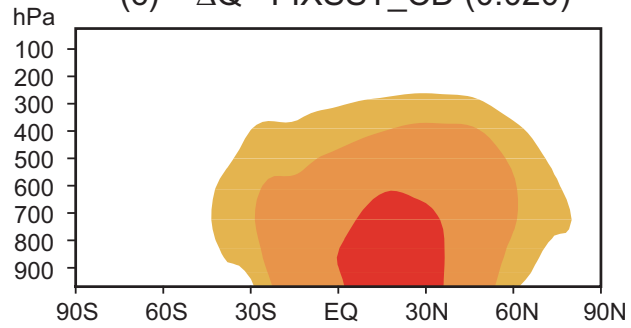

(d) $\triangle$ Prec FIXSST_CD (-0.01)

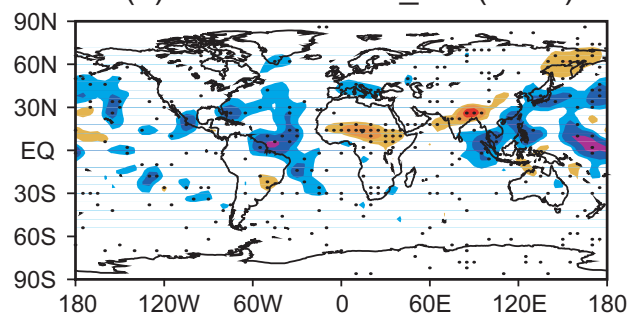

(e) $\triangle$ SAT MXLSST_CD (-0.09)
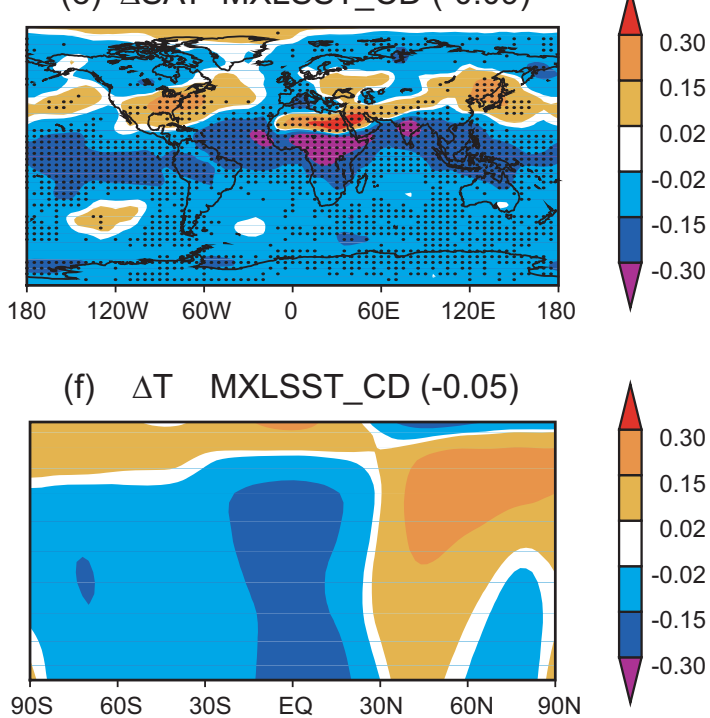

(g) $\triangle Q$ MXLSST_CD (-0.014)

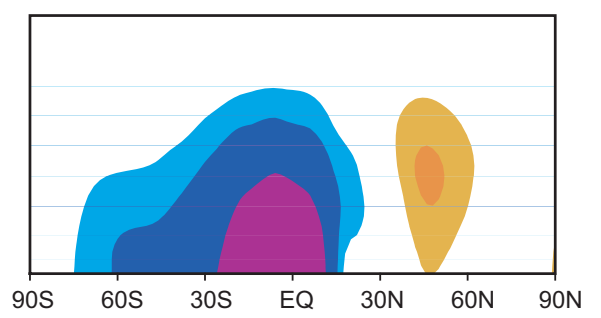

(h) $\triangle$ Prec MXLSST_CD (-0.03)

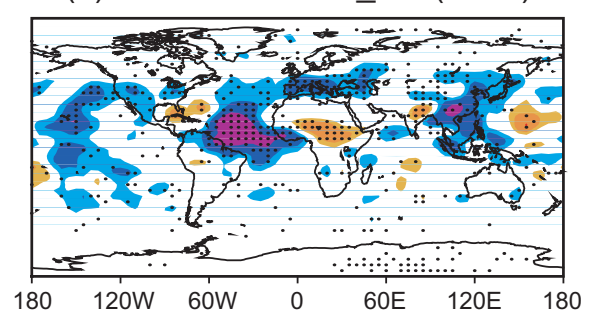

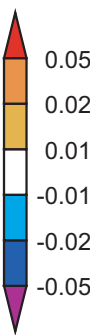

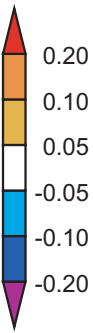

Fig. 7. Same as Fig. 4 but for dust-induced changes in meteorological fields with fixed SST and dust-climate coupling (FIXSST_CD FIXSST_CTRL, left panels) and with the mixed-layer ocean and dust-climate coupling (MXLSST_CD - MXLSST_CTRL, right panels).

surface to the upper troposphere over $90^{\circ} \mathrm{S}-30^{\circ} \mathrm{N}$ (Fig. 7f). On an annual and global mean basis, the dust-induced change in SAT is a cooling of $0.09 \mathrm{~K}$ in MXLSST_CD. Compared to simulations FIXSST_FD, MXLSST_FD, and FIXSST_CD, the strongest cooling for each season (Table 3 ) is obtained in MXLSST_CD because of the dust cycle-climate interactions.

\subsubsection{Hydrological cycle}

The pattern of simulated changes in precipitation in FIXSST_CD is similar to that in MXLSST_CD. However, simulated reductions in precipitation over the tropical At- lantic Ocean are larger in MXLSST_CD (Fig. 7h) than in FIXSST_CD (Fig. 7d), because of the reductions in evaporation (not shown) and the reduced water vapor content (Fig. 7g) in MXLSST_CD. Again, the reductions in evaporation (or latent heat flux) in MXLSST_CD are mainly caused by the dust-induced reductions in SSTs as discussed in Sect. 4.1.1. The zonal mean specific humidity exhibits reductions over $60^{\circ} \mathrm{S}-15^{\circ} \mathrm{N}$ in MXLSST_CD (Fig. 7g), corresponding to the dust-induced reductions in SST and air temperature (Fig. 7f). 
Table 4. Simulated percentage changes in annual and global mean dust burden in each size bin with FIXSST ((FIXSST_CDFIXSST_CTRL)/FIXSST_CTRL) and MXLSST ((MXLSST_CDMXLSST_CTRL)/MXLSST_CTRL).

\begin{tabular}{lrr}
\hline & FIXSST & MXLSST \\
\hline $0.1-1.0 \mu \mathrm{m}$ & $+14.5 \%$ & $+16.8 \%$ \\
$1.0-2.0 \mu \mathrm{m}$ & $+12.2 \%$ & $+14.4 \%$ \\
$2.0-5.0 \mu \mathrm{m}$ & $+8.9 \%$ & $+10.9 \%$ \\
$5.0-10.0 \mu \mathrm{m}$ & $+1.6 \%$ & $+3.0 \%$ \\
$1.0-10.0 \mu \mathrm{m}$ & $+10.4 \%$ & $+12.0 \%$ \\
\hline
\end{tabular}

\subsubsection{The dust cycle-climate feedbacks in FIXSST_CD and MXLSST_CD}

The role of SST responses has been shown to be important aforementioned. It is also found that the role of SST responses is enhanced with dust cycle-climate interactions. The reason for the strongest cooling in SAT and air temperature in MXLSST_CD is that the dust-induced changes in meteorological fields can feed back into simulated dust cycle and then influence the simulated ultimate dust burden and climate. Table 2 presents the simulated dust budget in MXLSST_CTRL and MXLSST_CD. Relative to MXLSST_CTRL, MXLSST_CD simulates a $2.4 \%$ lower global dust emission, because the dust-induced cooling in Central Africa (Fig. 7e) leads to a decrease in saturation specific humidity and hence an increase in surfacelayer relative humidity (not shown), which consequently reduces dust mobilization based on the dust generation function in Yue et al. (2009). However, simulated global dust burden exhibits an increase of $12.0 \%$ in MXLSST_CD relative to MXLSST_CTRL, as a result of the simulated reductions in precipitation (Fig. 7h). Because wet deposition is the only efficient way to remove small particles from the atmosphere, the dust-induced reductions in precipitation increase the burden of small particles (particles with radii $<1.0 \mu \mathrm{m}$ ) by $16.8 \%$ in MXLSST_CD relative to MXLSST_CTRL (Table 4). Dust particles in the size bin of $0.1-1.0 \mu \mathrm{m}$ have a net negative global mean forcing at TOA, whereas particles in each of larger size bins exert a net positive global mean TOA forcing (Yue et al., 2010). As a result, the increase in the burden of small particles by dust cycle-climate coupling contributes to the stronger global mean surface cooling in MXLSST_CD (Fig. 7e). Over the tropical oceans, the strong cooling in MXLSST_CD can also be explained by the positive feedback initialized by dust-induced cooling of SST. Dust-induced reductions in SST lead to reductions in evaporation and precipitation over the oceans, which increase column burdens of small dust particles and further reduce SSTs.
Relative to FIXSST_CTRL, the coupled dust-climate simulation FIXSST_CD also obtains an increase of $10.4 \%$ in total dust burden (Table 4), as a result of the dust-induced reductions in precipitation (Fig. 7d). However, without the positive feedback of "dust $\mathrm{RF} \rightarrow \mathrm{SST}$ response $\rightarrow$ climate $\rightarrow$ dust cycle", this increase in dust mass does not cause as strong cooling in FIXSST_CD as in MXLSST_CD.

The feedbacks in FIXSST_CD are summarized in Fig. 8a. The upward (or downward) arrow indicates an increase (or decrease) of a variable on a global scale. The atmospheric temperatures exhibit a widespread warming because of the net absorption by dust. Since SSTs are fixed in this experiment, the SAT is slightly increased by dust-induced absorption. The atmospheric warming increases the capability of atmosphere to hold water vapor and enhances atmospheric stability, leading to decreases in precipitation and MCA but increases in specific humidity. Since water vapor is a greenhouse gas in troposphere, the increases in water vapor content further contribute to the increases in air temperature.

The feedbacks in simulation MXLSST_CD are summarized in Fig. 8b. With MXLSST, SSTs decrease in response to the net negative dust RF at the surface, leading to reductions in upward latent heat flux by decreasing the saturated humidity at the ocean surface. Consequently, SAT, water vapor content and precipitation show decreases in the experiment. The upward sensible heat flux is also reduced as a result of the changes in both SST and SAT (the reductions in SST are larger than the reductions in SAT). In the lower and middle troposphere, the reductions in both latent and sensible heat fluxes from the ocean surface contribute to the strong atmospheric cooling over the tropical oceans. In the upper troposphere, the SW and LW absorption by dust plays the dominant role, resulting in a warming around $300 \mathrm{hPa}$. Such changes in air temperature increase the atmospheric stability. As a result, MCA and precipitation are reduced and dust burden is increased, leading to enhanced dust cycle-climate feedbacks.

\section{Conclusions and discussions}

The role of dust-induced SST responses in simulations of the climatic effect of dust is investigated by using a GCM coupled with a mixed layer ocean model. With the prescribed dust concentrations, the net radiative effect of dust is simulated to lead to similar responses in SAT over Africa with either FIXSST or MXLSST, with a maximum warming of $0.3-0.7 \mathrm{~K}$ in northern Africa and a cooling of about $0.5 \mathrm{~K}$ in central Africa. The simulated dust-induced changes in SAT over the tropical oceans with FIXSST differ from those with MXLSST; positive changes are simulated with FIXSST, while large areas of cooling are simulated with MXLSST. The annual and global mean SAT is simulated to increase by $0.02 \mathrm{~K}$ with FIXSST but to decrease by $0.03 \mathrm{~K}$ with MXLSST. 
(a) FIXSST

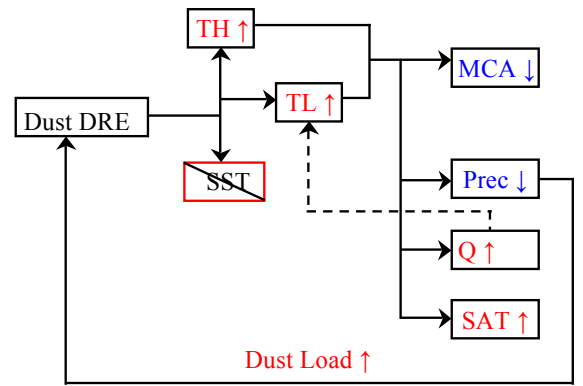

(b) MXLSST

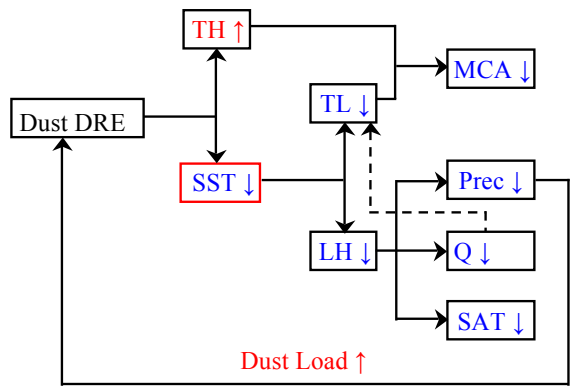

Fig. 8. Illustration of the interactions between dust and climate with (a) FIXSST and (b) MXLSST. The abbreviations stand for following variables: DRE: direct radiative effect; TH: air temperature at high troposphere; TL: air temperature at low troposphere; MCA: middle cloud amount; Prec: precipitation; Q: specific humidity; SAT: surface air temperature; LH: latent heat. The upward (or downward) arrow indicates an increase (or decrease) of a variable on a global scale.

The role of SST responses is enhanced when dust-climate interactions are included in climate simulations. With the two-way dust-climate coupling and the simulated SST, the radiative effect of dust leads to a strong annual and global mean cooling of $0.09 \mathrm{~K}$ at the surface. This cooling can be explained by the positive feedback between dust RF and SST responses. Dust RF leads to reduced SST, evaporation, and precipitation over the oceans, which increases the burden of small dust particles and further reduces SST (Fig. 8b). Experiments without such feedback by using prescribed SST and/or prescribed dust concentrations (FIXSST_FD, FIXSST_CD, and MXLSST_FD) predict, on an annual and global mean basis, a warming or a weak cooling at the surface or in the atmosphere as a result of dust RF.

Simulated air temperatures are also different between simulations with prescribed SST and calculated SST. In the upper troposphere, dust-induced changes in zonal mean air temperature are generally positive in simulations with either FIXSST or MXLSST. However, in the lower and middle troposphere, a columnar cooling over the tropical oceans is simulated with MXLSST. Although both simulations with prescribed SST and calculated SST predict decreases in precipitation in response to dust RF, the reduction in rainfall is larger over the tropical Atlantic Ocean in simulations with SST responses.

Our model results indicate that using a prescribed SST is not an adequate approach to study the climate response to dust radiative forcing and the feedbacks. Our conclusions are consistent with the findings in Yang et al. (2003), who carried out two sensitivity experiments to investigate the role of SST responses in simulating $\mathrm{CO}_{2}$-induced climate change. Yang et al. (2003) found in one sensitivity experiment that simulations with fixed SSTs predict a decrease in precipitation when atmospheric $\mathrm{CO}_{2}$ concentration is doubled, because of the limited evaporation from the oceans and the increased air stability induced by $\mathrm{CO}_{2}$ absorption in the atmosphere. This impact of fixed SSTs on precipitation is similar to that found out in FIXSST experiments, although we are examining radiative effect of dust instead of the radiative effect of $\mathrm{CO}_{2}$. Yang et al. (2003) found in another sensitivity experiment that both air temperature and precipitation decrease when the SSTs are reduced by $1^{\circ} \mathrm{C}$ globally, which agree qualitatively with our model results in MXLSST experiments. Besides some common features in Yang et al. (2003) and this work, we found in this study the role of SST responses is enhanced with the two-way coupling between dust-cycle and climate.

It should be noted that in our study the dust-induced decreases in SST are predicted to be $0.15-0.3 \mathrm{~K}$ over the Atlantic in MXLSST_CD (Fig. 7e), which are lower than the decreases of $0.2-0.5 \mathrm{~K}$ predicted by Mahowald et al. (2006) and Evan et al. (2008) over the same domains. This indicates that SST responses may play a more important role in simulation of dust-climate interactions than that found in this work.

Finally, there are some uncertainties in our simulations: (1) The imaginary part of the refractive index of dust utilized in this study may be larger than that inferred from observations (e.g. Kaufman et al., 2001). While the simulated SSA in our study is 0.94 at $0.63 \mu \mathrm{m}$ on a global mean basis, Kaufman et al. (2001) found that the SSA of the Saharan dust at $0.64 \mu \mathrm{m}$ is about 0.97 based on satellite and ground-based measurements. (2) Our simulations are carried out based on a mixed layer ocean model, which simplifies the heat flux exchange between atmosphere and ocean and omits the possible impacts of dust RF on the ocean circulation. A more comprehensive investigation of the SST feedback should be conducted by using climate models coupled with dynamical ocean components. (3) The indirect effect of dust aerosol is not considered in this work. Observations have shown that mineral dust can interact with cloud water droplets and influence the formation, lifetime, and optical properties of clouds (Sassen, 2002; Lohmann and Diehl, 2006; Huang et 
al., 2006a), leading to changes in cloud RF and precipitation (Huang et al., 2006b; Wang et al., 2010). Further consideration of dust indirect is the subject of our future study.

Acknowledgements. We would like to thank Yu Gu from the University of California, Los Angeles for her helpful comments on this study. This research was jointly supported by the National Natural Science Foundation of China (NNSFC) under grant 40825016, the National Basic Research Program of China ("973" program) under grant 2010CB951901, the NNSFC under grants 90711004 and 40631005, and the Key Project of Chinese Academy of Sciences under grants KZCX2-YW-Q11-03, and KZCX2-YW-Q1-02.

Edited by: Y. Balkanski

\section{References}

Ahn, H. J., Park, S. U., and Chang, L. S.: Effect of direct radiative forcing of Asian dust on the meteorological fields in East Asia during an Asian dust event period, J. Appl. Meteorol., 46, 16551681, doi:10.1175/JAM2551.1, 2007.

Avellaneda, N. M., Serra, N., Minnett, P. J., and Stammer, D.: Response of the eastern subtropical Atlantic SST to Saharan dust: A modeling and observational study, J. Geophys. Res., 115, C08015, doi:10.1029/2009JC005692, 2010.

Briegleb, B. P.: Delta-eddington approximation for solar radiation in the NCAR community climate model, J. Geophys. Res., 97, 7603-7612, doi:10.1029/92JD00291, 1992.

Carlson, T. N. and Benjamin, S. G.: Radiative heating rates for Saharan dust, J. Atmos. Sci., 37, 193-213, 1980.

Chidiezie, C. T., Bi, X., Wang, H., and Xue, F.: The African climate as predicted by the IAP grid-point nine-layer atmospheric general circulation model (IAP9L-AGCM), Adv. Atmos. Sci., 14, 409-416, doi:10.1007/s00376-997-0060-7, 1997.

Collier, J. C. and Zhang, G. J.: Aerosol direct forcing of the summer Indian monsoon as simulated by the NCAR CAM3, Clim. Dyn., 32, 313-332, doi:10.1007/s00382-008-0464-9, 2009.

Evan, A. T., Heidinger, A. K., Bennartz, R., Bennington, V., Mahowald, N. M., Corrada-Bravo, H., Velden, C. S., Myhre, G., and Kossin, J. P.: Ocean temperature forcing by aerosols across the Atlantic tropical cyclone development region, Geochem. Geophys. Geosyst., 9, Q05V04, doi:10.1029/2007GC001774, 2008.

Evan, A. T., Vimont, D. J., Heidinger, A. K., Kossin, J. P., and Bennartz, R.: The role of aerosols in the evolution of tropical North Atlantic Ocean temperature anomalies, Science, 324, 778781, doi:10.1126/science.1167404, 2009.

Foltz, G. R. and McPhaden, M. J.: Trends in Saharan dust and tropical Atlantic climate during 1980-2006, Geophys. Res. Lett., 35, L20706, doi:10.1029/2008GL035042, 2008.

Ginoux, P., Chin, M., Tegen, I., Prospero, J. M., Holben, B., Dubovik, O., and Lin, S.-J.: Sources and distributions of dust aerosols simulated with the GOCART model, J. Geophys. Res., 106, 20255-20273, doi:10.1029/2000JD000053, 2001.

$\mathrm{Gu}$, Y. and Liou, K. N.: Cirrus cloud horizontal and vertical inhomogeneity effects in a GCM, Meteorol. Atmos. Phys., 91, 223235, doi:10.1007/s00703-004-0099-2, 2006.

Hansen, J., Lacis, A., Rind, D., Russell, G., Stone, P., Fung, I., Ruedy, R., and Lerner, J.: Climate sensitivity: Analysis of feed- back mechanisms, in: Climate Processes and Climate Sensitivity, Geoph. Monog. Series., 29, 130-163 AGU, Washington, DC, USA, 1984.

Heinold, B., Helmert, J., Hellmuth, O., Wolke, R., Ansmann, A., Marticorena, B., Laurent, B., and Tegen, I.: Regional modeling of Saharan dust events using LM-MUSCAT: Model description and case studies, J. Geophys. Res., 112, D11204, doi:10.1029/2006JD007443, 2007.

Helmert, J., Heinold, B., Tegen, I., Hellmuth, O., and Wendisch, M.: On the direct and semidirect effects of Saharan dust over Europe: A modeling study, J. Geophys. Res., 112, D13208, doi:10.1029/2006JD007444, 2007.

Huang, J., Lin, B., Minnis, P., Wang, T., Wang, X., Hu, Y., Yi, Y., and Ayers, J. K.: Satellite-based assessment of possible dust aerosols semi-direct effect on cloud water path over East Asia, Geophys. Res. Lett., 33, L19802, doi:10.1029/2006GL026561, 2006 a.

Huang, J., Minnis, P., Lin, B., Wang, T., Yi, Y., Hu, Y., SunMack, S., and Ayers, K.: Possible influences of Asian dust aerosols on cloud properties and radiative forcing observed from MODIS and CERES, Geophys. Res. Lett., 33, L06824, doi:10.1029/2005GL024724, 2006b.

Huang, J., Minnis, P., Chen, B., Huang, Z., Liu, Z., Zhao, Q., Yi, Y., and Ayers, J. K.: Long-range transport and vertical structure of Asian dust from CALIPSO and surface measurements during PACDEX, J. Geophys. Res., 113, D23212, doi:10.1029/2008JD010620, 2008.

Jiang, D. B., Wang, H. J., Drange, H., and Lang, X. M.: Last Glacial Maximum over China: Sensitivities of climate to paleovegetation and Tibetan ice sheet, J. Geophys. Res., 108, 4102, doi:10.1029/2002JD002167, 2003.

Kaufman, Y. J., Tanré, D., Dubovik, O., Karnieli, A., and Remer, L. A.: Absorption of sunlight by dust as inferred from satellite and ground-based remote sensing, Geophys. Res. Lett., 28, 14791482, doi:10.1029/2000GL012647, 2001.

Konare, A., Zakey, A. S., Solmon, F., Giorgi, F., Rauscher, S., Ibrah, $\mathrm{S}$., and $\mathrm{Bi}, \mathrm{X}$.: A regional climate modeling study of the effect of desert dust on the West African monsoon, J. Geophys. Res., 113, D12206, doi:10.1029/2007JD009322, 2008.

Lau, K. M. and Kim, K. M.: Cooling of the Atlantic by Saharan dust, Geophys. Res. Lett., 34, L23811, doi:10.1029/2007GL031538, 2007.

Lau, K. M., Kim, M. K., and Kim, K. M.: Asian summer monsoon anomalies induced by aerosol direct forcing: the role of the Tibetan Plateau, Clim. Dynam., 26, 855-864, doi:10.1007/s00382006-0114-z, 2006.

Levitus, S., Antonov, J. I., Boyer, T. P., and Stephens, C.: Warming of the world ocean, Science, 287, 2225-2229, doi:10.1126/science.287.5461.2225, 2000.

Liang, X.: Description of a nine-level grid point atmospheric general circulation model, Adv. Atmos. Sci., 13, 269-298, doi:10.1007/BF02656847, 1996.

Liao, H., Seinfeld, J. H., Adams, P. J., and Mickley, L. J.: Global radiative forcing of coupled tropospheric ozone and aerosols in a unified general circulation model, J. Geophys. Res., 109, D16207, doi:10.1029/2003JD004456, 2004.

Lohmann, U. and Diehl, K.: Sensitivity studies of the importance of dust ice nuclei for the indirect aerosol effect on stratiform mixed-phase clouds, J. Atmos. Sci., 63, 968-982, 
doi:10.1175/JAS3662.1, 2006.

Luo, G., Yu, F. Q., and Wang, Z. F.: Impact of aerosol on sea surface temperature over the subtropical Atlantic Ocean: A potential trigger factor of the NAO phase conversion?, Geophys. Res. Lett., 36, L03708, doi:10.1029/2008GL036035, 2009.

Mahowald, N. M., Yoshioka, M., Collins, W. D., Conley, A. J., Fillmore, D. W., and Coleman, D. B.: Climate response and radiative forcing from mineral aerosols during the last glacial maximum, pre-industrial, current and doubled-carbon dioxide climates, Geophys. Res. Lett., 33, L20705, doi:10.1029/2006GL026126, 2006.

Miller, R. L. and Tegen, I.: Climate response to soil dust aerosols, J. Clim., 11, 3247-3267, 1998.

Miller, R. L., Perlwitz, J., and Tegen, I.: Feedback upon dust emission by dust radiative forcing through the planetary boundary layer, J. Geophys. Res., 109, D24209, doi:10.1029/2004JD004912, 2004a.

Miller, R. L., Perlwitz, J., and Tegen, I.: Modeling Arabian dust mobilization during the Asian summer monsoon: The effect of prescribed versus calculated SST, Geophys. Res. Lett., 31, L22214, doi:10.1029/2004GL020669, 2004b.

Mu, M. and Li, C.: ENSO signals in interannual variability of East Asian winter monsoon, Part II: simulated data analyses, Clim. Environ. Res., 4, 176-184, 1999 (in Chinese).

Perlwitz, J., Tegen, I., and Miller, R. L.: Interactive soil dust aerosol model in the GISS GCM: 1 . Sensitivity of the soil dust cycle to radiative properties of soil dust aerosols, J. Geophys. Res., 106, 18167-18192, doi:10.1029/2000JD900668, 2001.

Perlwitz, J. and Miller, R. L.: Cloud cover increase with increasing aerosol absorptivity: A counterexample to the conventional semidirect aerosol effect, J. Geophys. Res., 115, D08203, doi:10.1029/2009JD012637, 2010.

Ramanathan, V. and Downey, P.: A nonisothermal emissivity and absorptivity formulation for water vapor, J. Geophys. Res., 91, 8649-8666, doi:10.1029/JD091iD08p08649, 1986.

Reddy, M. S., Boucher, O., Bellouin, N., Schulz, M., Balkanski, Y., Dufresne, J. L., and Pham, M.: Estimates of global multicomponent aerosol optical depth and direct radiative perturbation in the Laboratoire de Meteorologie Dynamique general circulation model, J. Geophys. Res., 110, D10S16, doi:10.1029/2004JD004757, 2005.

Rodwell, M. J. and Jung, T.: Understanding the local and global impacts of model physics changes: An aerosol example, Q. J. R. Meteorol. Soc, Q. J. R. Meteorol. Soc., 134, 1479-1497, doi:10.1002/qj.298, 2008.

Sassen, K.: Indirect climate forcing over the western US from Asian dust storms, Geophys. Res. Lett., 29, 1465, doi:10.1029/2001GL014051, 2002.

Shell, K. M. and Somerville, R. C. J.: Direct radiative effect of mineral dust and volcanic aerosols in a simple aerosol climate model, J. Geophys. Res., 112, D03206, doi:10.1029/2006JD007198, 2007.

Sokolik, I. N. and Toon, O. B.: Direct radiative forcing by anthropogenic airborne mineral aerosols, Nature, 381, 681-683, doi:10.1038/381681a0, 1996

Solmon, F., Mallet, M., Elguindi, N., Giorgi, F., Zakey, A., and Konare, A.: Dust aerosol impact on regional precipitation over western Africa, mechanisms and sensitivity to absorption properties, Geophys. Res. Lett., 35, L24705,
doi:10.1029/2008GL035900, 2008.

Tegen, I. and Fung, I.: Modeling of mineral dust in the atmosphere: Sources, transport, and optical thickness, J. Geophys. Res., 99, 22897-22914, doi:10.1029/94JD01928, 1994.

Tegen, I. and Lacis, A. A.: Modeling of particle size distribution and its influence on the radiative properties of mineral dust aerosol, J. Geophys. Res., 101, 19237-19244, doi:10.1029/95JD03610, 1996.

Wang, W., Huang, J., Minnis, P., Hu, Y., Li, J., Huang, Z., Ayers, J. K., and Wang, T.: Dusty cloud properties and radiative forcing over dust source and downwind regions derived from A-Train data during the Pacific Dust Experiment J. Geophys. Res., 115, D00H35, doi:10.1029/2010JD014109, 2010.

Weaver, C. J., Ginoux, P., Hsu, N. C., Chou, M.-D., and Joiner, J.: Radiative forcing of Saharan dust: GOCART model simulations compared with ERBE data, J. Atmos. Sci., 59, 736-747, 2002.

Woodward, S.: Modeling the atmospheric life cycle and radiative impact of mineral dust in the Hadley Centre climate model, J. Geophys. Res., 106, 18155-18166, doi:10.1029/2000JD900795, 2001.

Xue, F., Bi, X., and Lin, Y.: Modelling the global monsoon system by IAP 9L AGCM, Adv. Atmos. Sci., 18, 404-412, doi:10.1007/BF02919319, 2001.

Yang, F., Kumar, A., Schlesinger, M. E., and Wang, W.: Intensity of hydrological cycles in warmer climates, J. Clim., 16, 2419-2423, doi:10.1175/2779.1, 2003.

Yoshioka, M., Mahowald, N. M., Conley, A. J., Collins, W. D., Fillmore, D. W., Zender, C. S., and Coleman, D. B.: Impact of desert dust radiative forcing on Sahel precipitation: relative importance of dust compared to sea surface temperature variations, vegetation changes, and greenhouse gas warming, J. Clim., 20, 14451467, doi:10.1175/JCLI4056.1, 2007.

Yue, X. and Wang, H. J.: The application of the CCM3/NCAR radiation scheme in IAP-AGCM, Chinese J. Atmos. Sci., 33, 16-28, 2009 (in Chinese).

Yue, X., Wang, H., Wang, Z., and Fan, K.: Simulation of dust aerosol radiative feedback using the Global Transport Model of Dust: 1. Dust cycle and validation, J. Geophys. Res., 114, D10202, doi:10.1029/2008JD010995, 2009.

Yue, X., Wang, H., Liao, H., and Fan, K.: Simulation of dust aerosol radiative feedback using the GMOD: 2. Dust-climate interactions, J. Geophys. Res., 115, D04201, doi:10.1029/2009JD012063, 2010.

Yue, X., Wang, H. J., Liao, H., and Jiang, D. B.: Simulation of the direct radiative effect of mineral dust aerosol on the climate at the Last Glacial Maximum, J. Clim., 24, 843-858, doi:10.1175/2010JCLI3827.1, 2011.

Zender, C. S., Bian, H., and Newman, D.: Mineral Dust Entrainment and Deposition (DEAD) model: Description and 1990s dust climatology, J. Geophys. Res., 108, 4416, doi:10.1029/2002JD002775, 2003.

Zeng, Q., Zhang, X., Liang, X., Yuan, C., and Chen, S. F.: Documentation of IAP two-level atmospheric general circulation model, DOE/ER/60314-H1, 383 pp., 1989.

Zhang, D. F., Zakey, A. S., Gao, X. J., Giorgi, F., and Solmon, F.: Simulation of dust aerosol and its regional feedbacks over East Asia using a regional climate model, Atmos. Chem. Phys., 9, 1095-1110, doi:10.5194/acp-9-1095-2009, 2009.

Zhang, X.: Dynamical framework of IAP nine-level atmospheric 
general circulation model, Adv. Atmos. Sci., 7, 67-77, doi:10.1007/BF02919169, 1990.

Zhang, Z. S., Wang, H. J., Guo, Z. T., and Jiang, D. B.: Impacts of tectonic changes on the reorganization of the Cenozoic paleoclimatic patterns in China, Earth Planet. Sci. Lett., 257, 622-634, doi:10.1016/j.eps1.2007.03.024, 2007.
Zhu, Y., Wang, H. J., Zhou, W., and Ma, J. H.: Recent changes in the summer precipitation pattern in East China and the background circulation, Clim. Dyn., 36, 1463-1473, doi:10.1007/s00382010-0852-9, 2010. 